Original Research Paper

\title{
Drought Tolerance and Evaluation of Genetic Changes in Rice Mutant Lines
}

\author{
Aryanti Amsal and Ishak-ishak \\ Agriculture, Centre for Isotop and Radiation Application (CIRA), National Nuclear Energy Agency, Indonesia
}

Article history

Received: 17-11-2017

Revised: 22-11-2017

Accepted: 12-01-2018

Corresponding Author: Aryanti Amsal

Agriculture, Centre for isotop and Radiation Application (CIRA), National Nuclear Energy Agency, Indonesia Email: aryanti@batan.go.id

\begin{abstract}
The genetic improvement of rice through mutation induction to obtain drought resistance is essential for stable and adequate rice production would enable us to anticipate the rice yield-reducing effects of global warming. The aim of this research was to evaluate the rice mutant lines showing tolerance to drought condition and their genetic relationship using SSR markers. Mutant lines were obtained by irradiation of Mira-1 rice variety at primordial state by 25 and 50 Gy doses. Twenty numbers of M4 rice mutant lines, cv. Mira-1 as wild type, cv. Gajah mungkur as positive control and cv. IR64 as negative control were chosen in this study were planted in PVC cylinders in the green house. The result showed that the agronomic trait of rice mutant lines were better than their wild type. Root length of 17 number of mutant lines are longer than their wild type and Gajah mungkur, the longest root obtain was $71.5 \mathrm{~cm}$ on $7 \mathrm{~J} 4$ rice mutant line compared to Mira-1 only which was $25 \mathrm{~cm}$. The number of lateral roots and seeds content per panicle higher than their wild type and positive control. Based on SSR marker linked to root depth, DRO1 showed that 12 numbers of mutant lines polymorphic and changing of genetic of mutant lines which was indicating the mutant lines were tolerant to drought compared to their wild type. The molecular information of rice mutant lines is essential for further development of a new superior variety of rice, which would be an improvement of the variety already existed.
\end{abstract}

Keywords: Rice Mutant Lines, Drought Tolerant, SSR Makers

\section{Introduction}

Rice (Oryza sativa L.) is a staple food for more than half population in the world (Krupa et al., 2017; Singh et al., 2016) and staple food for Indonesians (Widyanti et al., 2014). In Indonesia, rice cultivation covered a total of around 9 million hectares throughout the archipelago, primarily on irrigated system (Aryanti, 2016) However, the transfer of agricultural land to non productive area has been going on since the last decade, making it limitation of irrigated rice (Panuju et al., 2013). The expansion of rice cultivation to dry area is a very appropriate choice, because Indonesia has 148 million hectares of dry land (Adie and Krisnawati, 2014), therefore it is necessary to create new drought tolerance rice varieties. Until now, low progress of research in creating new cultivar of rice showing tolerance to drought. The strategy for the genetic improvement related to drought tolerance rice is very importance for new cultivar. One of strategy is the use of gamma rays for breeding programme in order to obtain superior allele in rice genome. Appropriate number of cultivars related to drought tolerance would control balance of supply and demand for food (Shereen et al., 2009; Suprasanna et al., 2014). Untill now, production of drought-resistance rice is very low, which could not contribute for improving of rice at a level of national production. To obtain superior varieties with high productivity and tolerance to drought prone some efforts have been conducted. In rice, multiple mutant collection has been established in diversed genetic background (Li et al., 2017; Wang et al., 2013; Wei et al., 2013).

Mutation induction by gamma rays have been contributed for improving of crops (Ichitani et al., 2014; Parry et al., 2009; Oladosu et al., 2016; Mustikarini et al., 2016), this technique has played an influential role in increasing the world food security. Since new food crop varieties embedded with various induced mutations have contributed to the significant increase of crop production. People could directly access and more easily observable traits could be created (Cieslak et al., 2017). According to International Atomic Energy Agency (IAEA), more than 400 rice varieties being developed worldwide (Li et al., 
2016) and NNEA/BATAN has released 21 of new rice varieties from this technique (Aryanti et al., 2017). Gamma rays produces Reactive Oxygen Species (ROS), which interact with DNA and cause oxidative damage such as base modifications and single/double strand breaks (Arjona and Ariza, 2009; Morita et al., 2009). The modifications base can be deleted, inversion and substitution (Shu et al., 2011) and plants can be mutated to dwarf, pest resistant and drought tolerant plants (Ashraf, 2010).

Ahmadikhah and Marufinia (2016) mentioned that drought stress due to water deficit is a major problem of rice cultivation as a most drought-sensitive crop plant. Abiotic stresses can affect the physiological status of an organism and have adverse effects on growth, development and metabolism (Chutia and Borah, 2012), which affects plants at various levels and stages of their life period. This abiotic stress not only affects plantwater relations through the reduction of water content, turgor and total water, but it also affects on stomatal closure, reduces transpiration and disturbs photosynthesis (Razak et al., 2013). The negative effects of water deficit will also decreases the nutrition and metabolism of leaves and alter assimilate partitioning among the plant organs (Zain et al., 2014). Rice varieties have differential responses to abiotic stresses because of the complexity of interactions between stress factors and various molecular, biochemical and physiological processes that affect plant growth and development (Hasanuzzaman et al., 2013).

Mutant lines indicated tolerance to drought in a selection processes, it should be showing relationship between phenotype and genotype. Based on reports from QTL and molecular data showed that a key gene has immediate response to drought and other biotic stressed Samota et al., 2017; Borah et al., 2017; Prince et al., 2015). The plant's phenotype showed tolerance to drought can be observed such as panicle length and fertile grains, roots length. The major focus in breeding rice for stress environment i.e., drought was on root architecture (Uga et al., 2013). Breeding for deep rooting is a promising strategy to improve the architecture of root system in shallow-rooting rice cultivars to avoid drought stress, like DRO1, a QTL for deep rooting on chromosome 9 (Uga et al., 2013). Many studies have suggested that a deep root system helps plants to avoid drought stress by extracting water from deep soil layers. According to Courtois et al. (2009), a total of 103 Quantitative Trait Loci (QTLs) for root length have been reported in rice. Obara et al. (2012), also fine-mapped qRL6.1, a QTL located on chromosome 6 and associated with root length in hydroponically grown rice seedlings has been reported.

Here we report the phenotypic character and genetic relation by SSR marker of rice mutant lines linked to drought tolerant within pipeline experiment. Molecular markers have proven to be powerful tools in the assessment of genetic variation and in the elucidation of genetic relationship or linked to trait of interest and help indirect selection of such complex traits within and among mutant lines (Mallikarjuna and Kumar 2013, Lima et al., 2015).

The objective of this study was to evaluate alteration of the agronomic and genetic characters of rice mutant lines indicated tolerance to drought in a selection progress.

\section{Methods}

\section{Rice Mutant Lines}

Mira-1 rice variety on primordia stages were irradiated with the doses of 25 and $50 \mathrm{~Gy}$ in the year of 2014, it used about 200 clumps for each dose, subsequently planted in the experimental field.

Selection was performed on M2 generation, where individual M1 yields were replanted on M2 plants. Selection of mutant lines was performed in M2, which was indicating drought tolerant trait, then planted and continues planted to obtain M4 generation. A test with Polyethylene Glycol (PEG) 20\% concentration was performed on 35 numbers of mutant lines. 30 Seeds per number of M4 generation of rice mutant lines placed in whole basket and soaked for 5 days and selected plants grown from this test rinsed with water and it used for this study.

\section{PVC Tube Cultivation}

To assess the variation in drought resistance among rice mutant lines, a protocol was developed based on single tiller propagation and PVC tube cultivation. Twenty numbers out of 35 of rice mutant lines grew well in $20 \%$ PEG solution, then it was planted on every $60 \mathrm{~cm}$ PVC pipe in green house. Observation of agronomy characters were conducted on plant height, length of flag leaves, panicle length, grains yield per panicle, number of productive tillers, root length and number of lateral roots.

\section{Plant Genomic DNA Extraction}

Young and fresh leaves of all individual rice mutant varieties and their wild type were stored at $-70^{\circ} \mathrm{C}$ until used for DNA extraction. DNA was isolated from the frozen leaves which were grounded by mortar and pestle under liquid nitrogen. BIOSPIN Kit Plant Genomic DNA extraction from Bioer Technology Co. Ltd, China was used for extraction. Fine powder was added with $450 \mu \mathrm{L}$ LP buffer, then mixed throughly and incubated at $65 \mathrm{oC}$ for $15 \mathrm{~min}$. After cooling at room temperature, the solution was added with $150 \mu \mathrm{L}$ DA buffer and mixed throughly, then incubated for $5 \mathrm{~min}$ in ice and spin at $12.000 \mathrm{rpm}$ using spin coloumn centrifuge. The solution was then removed to $1.5 \mathrm{~mL}$ new tube and added with $750 \mu \mathrm{L}$ of $\mathrm{P}$ binding buffer and spin again at $6000 \mathrm{rpm}$ for $1 \mathrm{~min}$, sediment in the coloumn was then added with $500 \mu \mathrm{L} \mathrm{G}$ binding buffer and centrifuge again for 30 
seconds. The sediment washed with $600 \mu \mathrm{L}$ washing buffer, centrifuge at $10.000 \mathrm{rpm}$ for $30 \mathrm{sec}$, the washing was done twice and added with $100 \mu \mathrm{L}$ elution buffer to obtain the DNA solution.

\section{Polymerase Chain Reaction (PCR)}

PCR reactions were performed in a $25 \mu \mathrm{L}$ reaction volume consisting of Go taq ${ }^{\circledR}$ green master mix $12.5 \mu \mathrm{L}$, forward and reverse primer $1.25 \mu \mathrm{L}$ each, nuclease free water $5 \mu \mathrm{L}$ and $5 \mu \mathrm{L}$ of rice DNA. PCR reaction was carried out under conditions (i) the denaturation at $94^{\circ} \mathrm{C}$ for $4 \mathrm{~min}$, (ii) denaturation during $1 \mathrm{~min}$ at $94{ }^{\circ} \mathrm{C}$, annealed for $1 \mathrm{~min}$ at the temperature of $55^{\circ} \mathrm{C}$, extension $72^{\circ} \mathrm{C}$ for $2 \mathrm{~min}$, extended extension $72^{\circ} \mathrm{C}$ for $5 \mathrm{~min}$, the number of cycles were 40 cycles. After amplification, 6 $\mu \mathrm{L}$ of products was combined with $1 \mu \mathrm{L}$ of a loading buffer and analyzed directly on $1 \%$ agarose and its running in electrophoresis for $45 \mathrm{~min}$ by using $100 \mathrm{bp}$ DNA ladder. The markers for detection of drought tolerant genetically were DRO1, RM 212, TM 302, RM 3825 and RM 470 (Kanagaraj et al., 2010; Krupa et al., 2017).

\section{Results and Discussion}

Identification of a drought-tolerant plant is commonly used Poly Ethylene Glycol (PEG 6000) solution, because the use of PEG (20\%) can reduce water potential to -1.3 Mega Pascal (Ishak, 1999). In this experiment used $20 \%$ PEG in a selection procedure for drought tolerance of rice mutant lines (Fig. 1). Mutant lines grew normally and no different root characters between roots of $28 \mathrm{H} 1$ mutant line and root of Gajah mungkur as positive control was shown.

Grain yield, tiller number, root lenght and lateral root were used as primary parameters for drought tolerance and compared to negative and positive control. Results showed that $28 \mathrm{H} 1$ mutant line provided 12 tiller number and $28,5 \mathrm{~cm}$ lenght of root within selection medium containg 20\% PEG (Table 1). The use of Gamma rays to hit cells target created mutation within genomic DNA and it caused alteration of genotypic structures when compared to its previous one. Alteration of genotypic structures can bee seen agronomic chatacters of mutant lines during selection process for drought tolerance. One of mutant lines i.e 20P1 produced 120 grains per panicle when compared to cv. Mira-1 as wild type (Table 1). Mutation provided some advantages for improving agronomic characters of rice mutant line. From 20 rice mutants planted in tube pipe only 2 of mutant lines were lower than their wild type. Plant height of mutant lines of $26 \mathrm{G} 1,26 \mathrm{~N} 1,30 \mathrm{~F} 1$ and $37 \mathrm{D} 3$ which were $81 \mathrm{~cm}$ showed no significant different compared to Gajah mungkur as positive control. These indicate that they are drought tolerant. Related to drought resistant of mutant lines on dry condition, roots are crucial for the successful of mutant lines growth at limited water conditions.

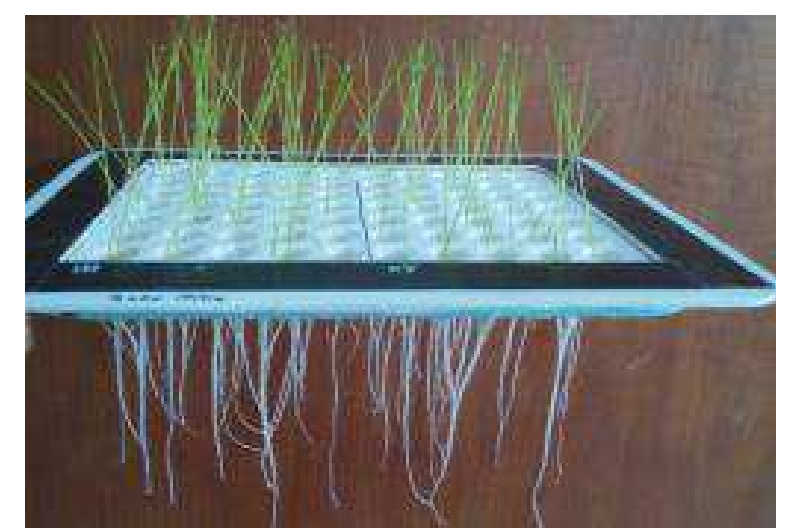

Fig. 1: Performance of cv. Gajah Mungkur (GM) and 28H1 mutant lines grown in medium containing PEG 20\%

Roots provide essential functions including the uptake of water and nutrients for plant growth, serve a role as storage organs, anchor the plants to the soil and place of interactions with pathogenic and beneficial organisms in the rhizosphere. The longest root obtained was $71.5 \mathrm{~cm}$ on $7 \mathrm{~J} 4$ mutant line which was almost three times longer than their wild type which was only 27.2 $\mathrm{cm}$. Mutant lines of 2J3 and 37D3 were also significant different of their root length compared to their wild type and positive control. The mutant line of $7 \mathrm{M} 1$ despite having a root length similar as their wild type plant, but it has the largest number of lateral roots which caused these mutant lines have more productive tillers than their wild type. About $75 \%$ of Root Length (RL) of mutant lines were longer than their wild type. Capacity of deep root growth and large xylem diameters in deep roots may improve root acquisition of water when ample water at depth is available (Paez-Garcia et al., 2015). Root morphology and physiology has an impact for the growth and development of plant organs. Such roots were able to transport mineral nutrients or diverse organic signaling molecules including hormones, proteins and RNAs.

The ability of roots to absorb water in dry conditions becomes a benchmark for identifying mutant line tolerant to drought. Agronomical properties like long root, solid and large diameter of the roots are used as indicator for drought tolerant. Drought-resistant rice generally has longer roots, larger root diameter than wild type and higher root penetration. Lateral roots can appear on any primary root, including embryonic and crown roots, which is initiated by local auxin transport. The higher number of lateral roots presented on Table 1. Data showed that the $28 \mathrm{H} 1$ mutant line has 142 lateral roots, it was then followed by mutant lines $30 \mathrm{~F} 1$ and $28 \mathrm{~F} 3$ of 100 and 78 lateral roots respectively. Although mutant lines $15 \mathrm{M} 1,26 \mathrm{C} 1$ and $26 \mathrm{G} 1$ have less than lateral roots when 
compared to their wild plant, but these of mutant lines have more productive tillers compared to Mira-1 and Gajah mungkur rice varieties. The Lateral Root (LR) was a main component of both the tap root and fibrous root systems, it was also the most active portion of the root system in water uptake, which comprise the majority of the length and surface area of root systems (Khan et al., 2016). According to Kao (2013) and Hsu et al. (2013), HEME OXYGENASE-1 (HOX1) gene controlling the formation of lateral root via the production of carbon monoxide, this gene was regulated by auxin and stress related signals and they suggested that this pathway can contribute to the modulation of root architecture in response to stress. Based on the numbers of lateral roots and root length of the rice mutant lines, mutation was caused by gamma rays and lead to as drought-resistant rice traits. The size of a plant's root system was the key trait that can affect the uptake of resources from the soil and should be considered in relation to the size of the above ground of plant parts. Increased lateral root density was associated with greater nutrient and water uptake. Diameter of roots also determine plants increase of hydraulic conductance efficiency by increasing surface area that could contact with soil water, increasing root hydraulic conductivity by decreasing the apoplastic barrier of water entering the xylem (Comas et al., 2013). It is generally acknowledged that a deeper, thicker and more branched root system with a high root to shoot ratio can enhance the tolerance of rice to water deficits
(Gowda et al., 2011). Genetic variability induced in rice through gamma rays for selecting new genotypes with improved grain rice quality and high yield potentials have been documented (Lima et al., 2015; Li et al., 2017). Various attempts have been made in this direction by different scientists to determine the most effective mutagenic treatment for the induction of desirable traits in rice. Induced mutations certainly have played a significantly effect of genes for increasing of lateral root rice mutant lines.

The number of productive tillers was one of the criteria for increasing rice production, because from the productive tiller will come out the panicle, the more productive tillers, the higher the panicles number obtained. The number of productive Tiller (TN) of mutant lines were differ significantly from their wild type and Gajah mungkur. The higher productive tiller were found on $28 \mathrm{H} 1$ and $30 \mathrm{~F} 1$ mutant lines, followed by mutant line of $20 \mathrm{P} 1$ which 11 productive tillers. The lowest productive tiller was found on $15 \mathrm{~L} 1$ mutant line, it was no significant different with their wild type (Table 1). However, this mutant line has a panicle length which was longer than the panicle length of their wild type. The agronomical selection of mutant lines were chosen by all performance of characters compared to their wild type and positive control plant of Gajah mungkur rice variety. Table 1 presented of productive tiller of mutant lines having better productive tillers than their wild type and this indicate that mutant lines grew well in dry condition.

Table 1: Agronomic characters of mutant lines compared to their wild type

\begin{tabular}{|c|c|c|c|c|c|c|c|}
\hline Mutant & $\mathrm{TN}$ & $\mathrm{PH}(\mathrm{Cm})$ & PL (Cm) & $\mathrm{FL}(\mathrm{Cm})$ & $\mathrm{RL}(\mathrm{Cm})$ & LR & GY \\
\hline$\overline{\mathrm{GM}}$ & 2 & $85,6.0$ & $38,5.0$ & $18,4.0$ & 35.0 & 15 & 64 \\
\hline IR 64 & 3 & $70,2.0$ & $25,4.0$ & $20,8.0$ & 25.0 & 8 & 36 \\
\hline Miral & 4 & $70,1.0$ & $19,4.0$ & 19.0 & $27,2.0$ & 38 & 56 \\
\hline $2 \mathrm{~J} 3$ & 5 & 69.0 & 32.0 & 23.0 & 51.3 & 26 & 64 \\
\hline $7 \mathrm{~J} 4$ & 7 & 67.5 & 31.0 & 20.0 & 71.5 & 46 & 63 \\
\hline 7L6 & 8 & 67.2 & 25.7 & 20.0 & 31.0 & 11 & 62 \\
\hline $7 \mathrm{M} 1$ & 7 & 65.0 & 28.4 & 19.0 & 26.7 & 50 & 64 \\
\hline 9G1 & 8 & 72.0 & 29.0 & 19.0 & 44.0 & 21 & 96 \\
\hline $15 \mathrm{~J} 4$ & 5 & 68.0 & 18.0 & 20.0 & 41.0 & 43 & 46 \\
\hline $15 \mathrm{~L} 1$ & 4 & 77.0 & 32.0 & 24.0 & 47.0 & 21 & 80 \\
\hline $15 \mathrm{M} 1$ & 7 & 73.0 & 35.5 & 21.0 & 33.0 & 16 & 78 \\
\hline 20M1 & 4 & 72.0 & 27.0 & 18.5 & 40.7 & 42 & 106 \\
\hline 20P1 & 11 & 79.0 & 30.5 & 21.6 & 33.0 & 22 & 120 \\
\hline $26 \mathrm{C} 1$ & 7 & 79.5 & 25.0 & 23.5 & 38.0 & 14 & 110 \\
\hline $26 \mathrm{G} 1$ & 5 & 81.0 & 29.0 & 22.0 & 43.0 & 17 & 110 \\
\hline $26 \mathrm{~N} 1$ & 9 & 80.3 & 19.6 & 21.4 & 30.0 & 25 & 72 \\
\hline $28 \mathrm{H} 1$ & 12 & 67.5 & 34.0 & 21.0 & 28.5 & 142 & 80 \\
\hline $28 \mathrm{~F} 3$ & 6 & 71.0 & 21.7 & 21.5 & 31.3 & 78 & 70 \\
\hline $30 \mathrm{~A} 1$ & 5 & 74.0 & 25.5 & 21.0 & 45.0 & 32 & 32 \\
\hline $30 \mathrm{~F} 1$ & 12 & 80.0 & 33.5 & 24.0 & 39.2 & 100 & 124 \\
\hline $34 \mathrm{D} 1$ & 7 & 65.5 & 29.0 & 17.5 & 41.0 & 26 & 70 \\
\hline 37D3 & 8 & 81.0 & 28.0 & 25.0 & 52.5 & 23 & 82 \\
\hline 39U2 & 5 & 67.4 & 36.0 & 19.5 & 33.2 & 62 & 82 \\
\hline
\end{tabular}

Notes: Tiller Number (TN); Plant Height (PH); Panicle Length (PL); Flag Leave Length (FL); Root Length (RL); Lateral Root (LR); Grain Yield per panicle (GY) 
Panicle Length (PL) and Flag Leaf (FL) are also the criterion for selected mutant lines. The panicle length of Gajah mungkur as positive control showed the longest panicle length than all of the selected mutant lines, however, no significant difference occurred compared to $39 \mathrm{U} 2$ and 15M1, with PL of mutant lines 36 and $35.5 \mathrm{~cm}$ respectively. The panicle length of these mutant lines two times longer than their wild type and about $85 \%$ of mutants have panicle length longer than their wild type. Rice varieties have different responses to abiotic stresses because of the complexity of interactions between stress factors and various molecular, biochemical and physiological processes that affect plant growth and development (Hasanuzzaman et al., 2013).

Multiple studies have identified links between roots and crop productivity under drought condition (Pandey and Shukla, 2015). Mutant lines 20M1, 28H1, $30 \mathrm{~F} 1$ have the largest percent grain content per panicle compared to other mutant lines and their wild type and Gajah mungkur. The percentage of grain content of those mutant lines are $64.63,57.45$ and $55.36 \%$ respectively compared to their wild type which is only $42.42 \%$. The high of grain content per panicle above their wild type is an indicator that gamma rays have affected mutation which was expressed as drought tolerant.

Performance of rice mutant lines and control plants were displayed in Fig. 2, which was observed in green house and some roots characters of rice mutant plants taken after harvesting. The genetic effects of mutagenic treatment are either based on phenotypic data and selected genes of genomic region (Yoshihara et al., 2013; Nawaz and Shu, 2014).

Molecular genetic tools have been adopted to characterize mutation induced by physical or chemical mutagens, which has revealed feature of induced mutations and the estimation of mutation occurred in various plants. Identification of drought tolerant of rice mutant lines by using five markers were related to roots and shoot as displayed in Fig. 3 for DRO1 and RM 212.

The results indicated the ability of markers to identify the allelic diversity and genetic variation among the studied rice genotypes. Allelic variability among mutant lines and wild type can be seen on Table 2. Figure 3 displayed that Gajah mungkur as positive control, IR64 as negative control and Mira-1 as wild type shown significant different compare to 20 numbers of mutant lines toward DRO1, where all mutant lines shown band size at $180 \mathrm{bp}$. Gene related to a root development QTL is DEEPER ROOTING 1 (DRO1) and is located at chromosome 9, which controls root growth angle and enhance deep rooting (Uga et al., 2013). Induced mutation had affected base sequence of chromosome 9 of Mira-1 and positive to DRO1. DRO1 related to agronomical character of root lenght show that root lenght of rice mutant lines are longer than their control plants (Table 1) and can improve the trait to soil drought stress. DRO1 encodes unkown protein that is expressed in root tips, a putative auxin response element in its promoter region specifically interacted with AUXIN RESPONSE FACTOR (ARF), moreover DRO1 participates in asymmetric cell elongation in root tips (Uga et al., 2015). DRO1 modulated root gravitopic response, likely via a modulation of epidermal cell elongation that enables roots to orientate their growth relative to the pull of gravity (Mai et al., 2014). From the Fig. 3 shows the alleles appeared by RM 302, RM 3825 and RM 470 markers respectively. It was determined that those markers could be useful for selecting drought tolerant lines through MAS approach. Three markers used were located on chromosome 1 of rice droughtresistant. The amplicon size of all genotypes for each marker alleles varied from 85 - 160 bp produced by RM 212, from 100-200 bp produced by RM 302 and $90-$ 230 bp produced by RM 3825. Polymorphic alleles (2) were obtained by mutant lines for those of primers, however, none polymorphic at IR64. These primers has been found to be linked with several drought resistance traits such as plant height, biomass, deep root mass, leaf drying, relative water content, osmotic adjustment, basal root thickness, tiller number and deep root to shoot ratio, grain yield and panicle length, canopy temperature in the IR20/Nootripathu RI lines (Kanagaraj et al., 2010).

The marker RM 470 used located on chromosome 4 had association with the transpiration rate trait, stomatal conductance and relative water content of plants under stress condition. Figure 3 displayed that all control plants and wild type are negative toward this marker used together with $2 \mathrm{~J} 3$ and $15 \mathrm{~L} 1$ mutant lines, another 18 mutant lines shown two alleles from those of mutant lines detected, $85 \%$ of mutant lines were polymorphic to the marker used. Gamma rays is a physical mutagenic, producing free radicals from water radiolysis, free radicals is an unstable spur which would attack the chemical bonds randomly including chromosome and DNA of plants (Lee et al., 2016; Tanaka et al., 2010). The existence of genetic differences between the parents with their mutant can be assumed that the plants have been mutated. Previous studies by Morita et al. (2009); Nawaz and Shu (2014) mutant genes showed that gamma irradiation induced mutations consisted mainly of deletion. However, Li et al. (2016) reported that Single Base Substitution (SBS) and short insertion/deletion (Indel) mutations were detected. They also report that transition found at $\mathrm{C}: \mathrm{G}>\mathrm{T}: \mathrm{A}$ and $\mathrm{T}: \mathrm{A}>$ $\mathrm{C}: \mathrm{G}$, transversion $\mathrm{C}: \mathrm{G}>\mathrm{A}: \mathrm{T} ; \mathrm{C}: \mathrm{G}>\mathrm{G}: \mathrm{C}$, single base deletion and transversion were the most frequent mutation. Belfield et al. (2012) mentioned that more single base sequence was detected than Indels.

Different types of changes in SSRs such as band disappearance and shifted band position were observed 
among mutant plants compared to their wild type, it indicates that gamma rays affected base sequence of Mira-1 mutant lines. Ionizing radiations cause mutations by breaking chemical bonds in the DNA molecule, deleting a nucleotide, or substituting it with a new one (Hwang et al., 2017) Basically, transitions and transversions are the simplest kinds of base pair changes, but they may result in phenotypically visible mutations. Tanaka et al. (2010) mentioned that ionizing radiation could generate many kinds of phenotypes, it induces DNA damage relatively randomly and series mutations can be occurred (Morita et al., 2009; Pacher and Puchta, 2017). Li et al. (2017) reported that fast-neutron mutant collection of Kitaake found 32,307 genes or 58\% of all genes in the rice genome are mutated, SBS are the most variant, deletion smaller than $100 \mathrm{bp}$ account nearly $90 \%$ of all deletions.

Table 2: The allele number of mutant lines by DRO1, RM 212, RM 302, RM 3825, RM 470 markers

\begin{tabular}{|c|c|c|c|c|c|}
\hline Mutant lines & DROI & RM 212 & RM 302 & RM 3825 & RM 470 \\
\hline$\overline{\mathrm{GM}}$ & 0 & 2 & 1 & 1 & 0 \\
\hline IR64 & 0 & 0 & 1 & 2 & 0 \\
\hline Mira & 0 & 2 & 2 & 0 & 0 \\
\hline $2 \mathrm{~J} 3$ & 1 & 1 & 2 & 2 & 0 \\
\hline $7 \mathrm{~J} 4$ & 1 & 2 & 2 & 2 & 2 \\
\hline 7L6 & 1 & 2 & 2 & 2 & 2 \\
\hline $7 \mathrm{M} 1$ & 1 & 2 & 2 & 2 & 2 \\
\hline 9G1 & 1 & 2 & 2 & 2 & 2 \\
\hline $15 \mathrm{~J} 4$ & 1 & 2 & 2 & 2 & 2 \\
\hline $15 \mathrm{~L} 1$ & 1 & 2 & 2 & 2 & 0 \\
\hline $15 \mathrm{M} 1$ & 1 & 2 & 2 & 2 & 2 \\
\hline $20 \mathrm{M} 1$ & 1 & 2 & 2 & 2 & 2 \\
\hline $20 \mathrm{P} 1$ & 1 & 2 & 2 & 2 & 2 \\
\hline $26 \mathrm{C} 1$ & 1 & 2 & 2 & 2 & 2 \\
\hline $26 \mathrm{G} 1$ & 1 & 0 & 2 & 2 & 2 \\
\hline $26 \mathrm{~N} 1$ & 1 & 2 & 2 & 2 & 2 \\
\hline $28 \mathrm{H} 1$ & 1 & 2 & 2 & 2 & 2 \\
\hline $28 \mathrm{~F} 3$ & 1 & 2 & 2 & 2 & 2 \\
\hline $30 \mathrm{~A} 1$ & 1 & 2 & 2 & 2 & 2 \\
\hline $30 \mathrm{~F} 1$ & 1 & 2 & 2 & 2 & 2 \\
\hline 34D1 & 1 & 2 & 2 & 2 & 2 \\
\hline 37D3 & 1 & 2 & 2 & 2 & 2 \\
\hline 39U2 & 1 & 2 & 2 & 2 & 2 \\
\hline
\end{tabular}
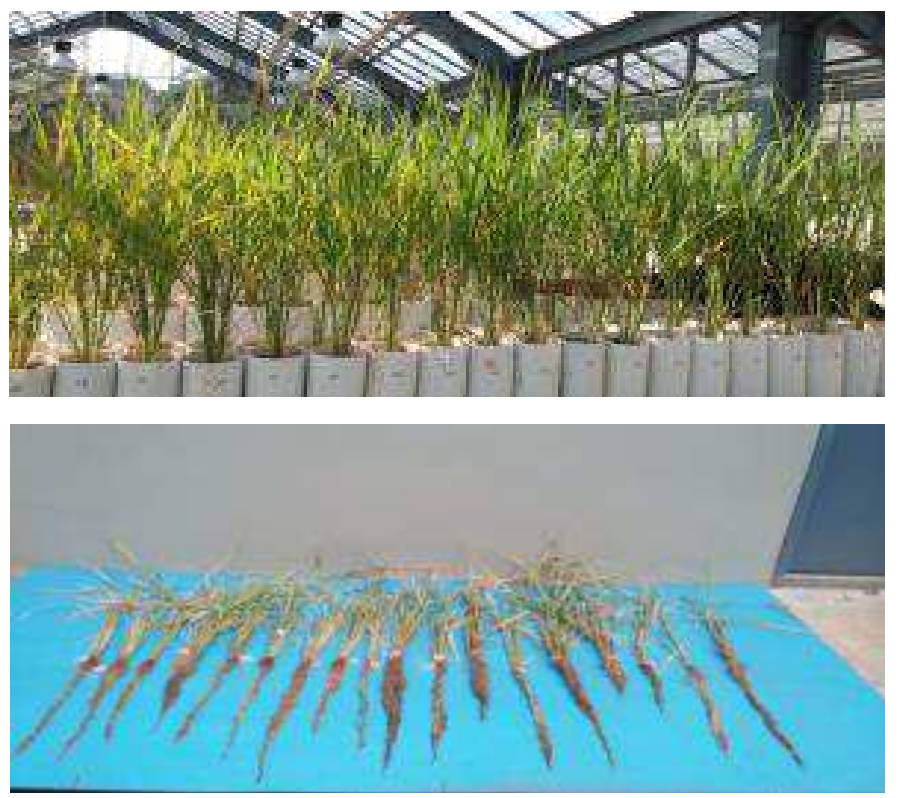

Fig. 2: Morphology of plants at green house and roots characteristic of mutant lines after harvesting 


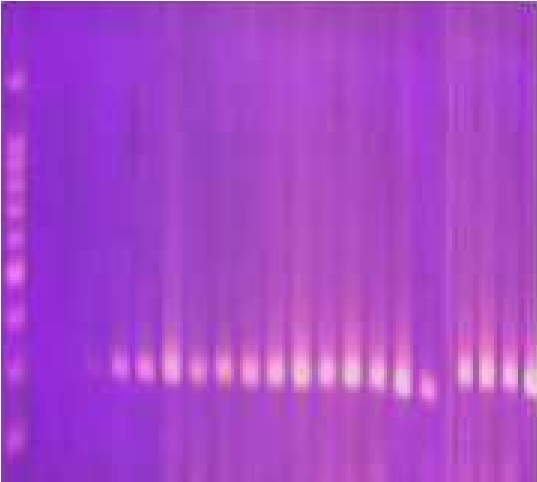

(a)

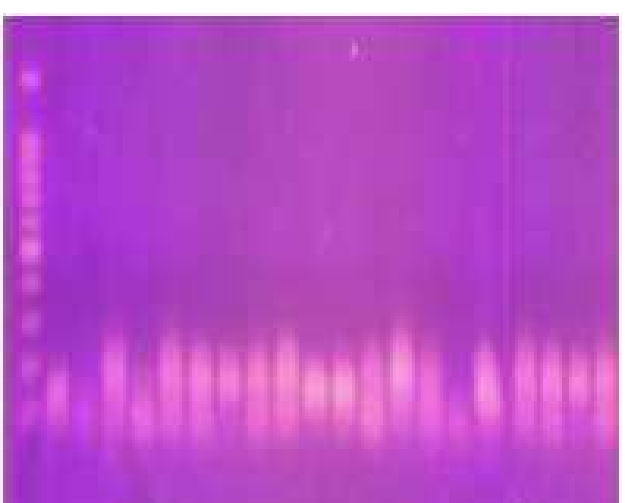

(b)

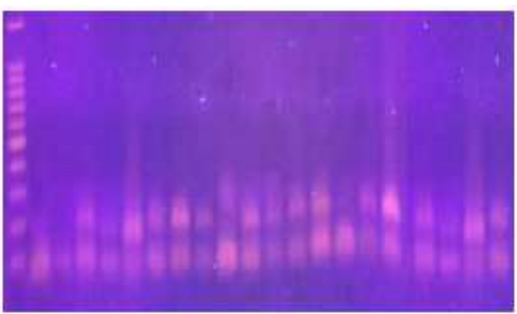

(c)

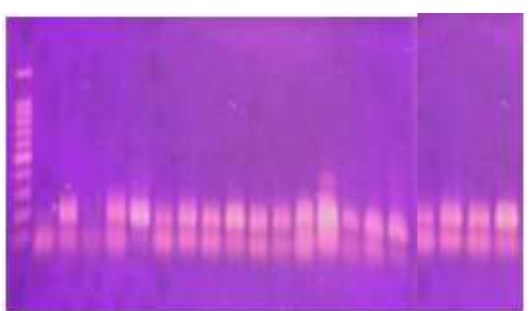

(d)

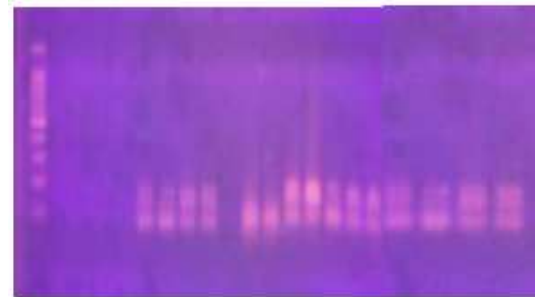

(e)

Fig. 3: The amplification of rice mutant lines with DRO1 (a), RM 212 (b), RM 302 (c), RM 3824 (d) and RM 470 1.marker; 2. GM; 3. IR64; 4.Mira-1; 5. 2J3; 6. 7J4; 7. 7M1; 8. 9G1; 9. 15J4; 10. 15L1; 11. 15M1; 12. $20 \mathrm{M1;} \mathrm{13.} \mathrm{20P1;} \mathrm{14.} \mathrm{26} \mathrm{C1;} \mathrm{15.} 26$ G1; 16. $26 \mathrm{~N} 1 ; 17.28 \mathrm{H} 1 ; 18.28 \mathrm{~F} 3 ; 19.34 \mathrm{D} 1 ; 20.37 \mathrm{D} 3 ; 21.39 \mathrm{U} 2$

According to Oladosu et al. (2016), among the various kinds of mutational changes at the molecular level are base substitutions, a term meaning nucleotide changes that involve substitution of one base for another. This can happen through mis-pairing of the base analogue in the treated DNA during replication, leading to mutation through transitions when exchanges occur either between purines (A to $G$ ) or between pyrimidines ( $T$ to $C$ ) and transversions when purines are exchanged for pyrimidines or vice versa (A, G T, C). Another common error would be addition or deletion of a nucleotide base pair when one of the bases manages to pair with two bases or fails to pair at all. These kinds of sequence changes resulting in an alteration in the reading frame of the gene's DNA are known as frame-shift mutations. Some of the mutations occur from rearrangement of bases in the DNA. A small or large sequence of bases may be inverted as a result of chromosome breakage and reunion of the broken ends may involve different DNA molecules in a reciprocal rearrangement or in loss of a fragment.

Forward genetics works starting from traits (phenotypes) in the field to genes and is the typical approach in plant breeding, genetics and genomics studies. Plant development patterns can also be significantly altered by mutations in gene coding regions. For example, homeobox genes in plants are involved in meristem maintenance and the development of lateral organs (Shu et al., 2011).

\section{Conclusion}

Rice at primordial state is very effective to mutation by gamma rays by low doses. Gamma rays has affected to improving of panicle length, root length, lateral root number which was related to drought tolerant. Five markers used were linked to root length, among them DRO1 was very effective for identification of drought tolerant. Mutant lines were tolerant to drought condition within phenotypic and genetic identification. The best characters found at $28 \mathrm{H} 1$ and $30 \mathrm{~F} 1$ mutant lines respectively. The methods for evaluation of mutant lines by phenotypic in line with genetic, that is short way to get the target properties.

\section{Acknowledgment}

Thank you to Mr Hery Irmawan, Dadang Sunendar and Mr. Nana Supriatna for helping in the green house experiment, also to Mrs. Almaida and Mrs. Rika Heryani for their molecular identification. This works was supported by National Research Incentive from Technological Research and Higher Education Ministry.

\section{Author's Contributions}

Aryanti Amsal: Data analysis and writing paper. Ishak-Ishak: Molecular and writing correction. 


\section{Ethics}

This article is original and contains unpublished material. The corresponding author confirms that all of the other authors have read and approved the manuscript and no ethical issues involved.

\section{References}

Adie, M.M. and A Krisnawati, 2014. Soybean opportunity as source of new energy in Indonesia. Int. J. Rebewable Energy Dev., 3: 37-43.

Ahmadikhah, A. and A. Marufinia, 2016. Effect of reduced plant height on drought tolerance in rice. 3Biotech, 6: 1-9.

Arjona, T.R. and R.R. Ariza, 2009. Repair and tolerance of oxidative DNA damage in plants. Mutation Res., 681: 169-179.

Aryanti, 2016. Germinated rice mutant lines at PEG various concentrations. Proceedings of the National Chemist Symposium, (NCS' 16), Jogyakarta, pp: 339-344.

Aryanti, A., I. Dwimahyani and I. Ishak, 2017. Identification of heading date six (Hd6) gene derived from rice mutant varieties. J. Biol. Educ., 9: 105-112.

Ashraf, M., 2010. Inducing drought tolerance in plants: Recent advances. Biotechnol. Adv., 28: 169-183.

Belfield, E.J., X. Gan, A. Mithani, C. Brown and C. Jiang et al., 2012. Genome-wide analysis of mutations in mutant lineages selected following fastneutron irradiation mutagenesis of Arabidopsis thaliana. Genome Res., 22: 1306-1315.

Borah, P., E. Sharma, A. Kaur, G. Chandel and G. Mohaputra et al., 2017. Analysis of drought-responsive signalling network in two contrasting rice cultivars using transcriptome-based approach. Sci. Rep.

Chutia, J. and S.P. Borah, 2012. Water stress effects on leaf growth and chlorophyll content but not the grain yield in traditional rice (Oryza sativa Linn.). Genotypes of Assam, India II. Protein and Proline Status in Seedlings under PEG Induced Water Stress. Am. J. Plant Sci., 3: 971-980.

Comas, L.H., S.R. Becker, V.M. Cruz, P.F. Byrne and D.A. Dierig, 2013. Root traits contributing to plant productivity under drought. Plant Sci., 4: 1-16. DOI: $10.3389 /$ fpls.2013.00442

Courtois, B., N. Ahmadi, F. Khowaja, A.H. Price and J.F. Rami et al., 2009. Rice root genetic architecture: Meta-analysis from a drought QTL database. Rice, 2: 115-128.

Cieslak, J.J., T.H. Tai, J. Kumlehn and B.J. Till, 2017. Biotechnologies for plant mutation breeding. Springer.

Gowda, V.R.P., A. Henry, A. Yamauchi, H.E. Shashidhar and R. Serraj, 2011. Root biology and genetic improvement for drought avoidance in rice. Field Crops Res. DOI: 10.1016/j.fcr.2011.03.001
Paez-Garcia, A., C.M. Motes, W.R. Scheible, R. Chen and E.B. Blancaflor et al., 2015. Root traits and phenotyping strategies for plant improvement. Plants, 4: 334-355.

Hasanuzzaman, M., K. Nahar, M.M. Alam, R. Roychowdhury and M. Fujita, 2013. Physiological, biochemical and molecular mechanisms of heat stress tolerance in plants. Int. J. Mol. Sci., 14: 9643-9684.

Hsu, Y.Y., Y.Y. Chao and C.H. Kao, 2013. Methyl jasmonate-induced lateral root formation in rice: The role of hemeoxygenase and calcium. J. Plant Physiol., 170: 63-69.

Hwang, J.E., D.S. Jang, K.L. Lee, J.W. Ahn and S.H. Kim et al., 2017. Identification of gamma ray irradiation-induced mutations in membrane transport genes in a rice population by TILLING. Genes Genet. Syst., 91: 245-256. DOI: $10.1266 /$ ggs. 15-00052

Ichitani, K., D. Yamaguchi, S. Taura, Y. Fukutoku and M. Onoue et al., 2014. Genetic analysis of ion beam induced extremely late heading mutants in rice. Breeding Sci., 64: 222-230.

Ishak, 1999. In vitro drought tolerant test and Identification of Rice Mutant Lines using RAPD Marker. J. Agricultural Biotechnol., 4: 61-66

Kanagaraj, P., K. Prince, J.A. Sheeba, K.R. Biji and S.B. Paul et al., 2010. Microsatellite markers linked to drought resistance in rice (Oryza sativa L.) Current Sci., 98: 25-25.

Kao, C.H., 2013. Role of rice heme oxygenase in lateral root formation. Plant Signaling Behavior, 8: e25766-e25766. DOI: 10.4161/psb.25766

Khan, M.A., C.G. Dorcus and A. Villordon, 2016. Root system architecture and abiotic stress tolerance: Current knowledge in root and tuber crops. Front Plant Sci. DOI: 10.3389/fpls.2016.01584

Krupa, K.N., H.E. Shashidhar, N. Dalawai, M. Reddy and V.H. Swamy, 2017. Molecular marker based genetic diversity analysis in rice genotypes (Oryza sativa L.) using SSR markers. Int. J. Pure Applied. Biosci., 5: 668-674.

Lee, H.J., Y.S. Kim, Y.D. Jo, B.K. Ha and D.S Kim et al., 2016. Oxidative stress and DNA damage induced by gamma irradiation in Korean lawngrass (Zoysia japonica Steud.). Eur. J. Hortic. Sci., 81: 303-309.

Li, S., Y.C. Zheng, H. Cui, H. Fu and Q.Y. Shu et al., 2016. Frequency and type of inheritable mutations induced by $\gamma$ rays in rice as revealed by whole genome sequencing. J. Zhejiang Univ. Sci. B, 17: 905-915. DOI: 10.1631/jzus.B1600125

Li, G., R. Jain, M. Chern, N.T. Pham and J.A. Martin et al., 2017. The sequences of 1,504 mutants in the model rice variety Kitaake facilitate rapid functional genomic studies. Plant Cell Advance Publication.

DOI: $10.1105 /$ tpc. 17.00154 
Lima, J.M., J.M. Nath, P. Dokku, K.V. Raman and K.P. Kulkarni et al., 2015. Physiological, anatomical and transcriptional alterations in a rice mutant leading to enhanced water stress tolerance. AoB Plants.

DOI: $10.1093 /$ aobpla/plv023

Mai, C.D., T.P. Nhung, T.M. Huong, M. Gonin and G.T. Hoang et al., 2014. Genes controlling root development in rice. Rice, 7: 30-30.

Mallikarjuna, S.B.P. and A. Kumar, 2013. Genomicsbased precision breeding approaches to improve drought tolerance in rice. Biotechnol. Adv., 31: 1308-1318.

Morita, R., M. Kusaba, S. Iida, H. Yamaguchi and T. Nishio et al., 2009. Molecular characterization of mutations induced by gamma irradiation in rice. Genes Genet. Syst., 84: 361-370.

Mustikarini, E.D., N.R. Ardiarini, N. Basuki and Kuswanto, 2016. The improvement of early maturity red rice mutant trait for drought tolerance. Int. J. Plant Biol., 7: 6345-6345. DOI: $10.4081 / \mathrm{pb} .2016 .6345$

Nawaz, Z. and Q.Y. Shu, 2014. Molecular nature of chemically and physically induced mutants in plants: A review. Proceeding of 3rd International Symposium on Genomic Plants Genetics Resorves, (PGR'14), pp: 574-578. DOI: $10.1017 / \mathrm{S} 1479262114000318$

Oladosu, Y., M.Y. Rafii, N. Abdullah, G. Hussin and A. Ramli et al., 2016. Principle and application of plant mutagenesis in crop improvement: A review. Biotechnol. Biotechnol. Equipment, 30: 1-16.

Obara, M., W. Tamura, T. Ebitani, M. Yano and T. Sato et al., 2010. Fine-mapping of qRL6.1, a major QTL for root length of rice seedlings grown under a wide range of $\mathrm{NH} 4+$ concentrations in hydroponic conditions. Theor Applied Genet, 121: 535-547.

Pacher, M. and M. Puchta, 2017. From classical mutagenesis to nuclease-based breeding- directing natural DNA repair for a natural end-product. Plant J., 90: 819-833

Pandey, V. and A. Ahukla, 2015. Acclimation and tolerance strategies of rice under drought stress. Rice Sci., 22: 147-161.

Panuju, D.R., K. Mizuno and B.H Trisasongko, 2013. The dynamics of rice production in Indonesia 19612009. J. Saudi Society Agricultural Sci., 12: 27-37.

Prince, S.J., R. Beena, S.M. Gomez, S. Senthivel and R.C. Babu, 2015. Mapping consistent rice (Oryza sativa L.) yield QTLs under drought stress in target rainfed environments. Rice, 8: 25-25.

Parry, M.A.J., P.J. Madgwick, C. Bayon, K. Tearall and A.H. Lopez et al., 2009. Mutation discovery for crop improvement. Experimental Botany, 60: 2817-2825.

Razak, A.A., M.R. Ismail, M.F. Karim, P.E.M. Wahab and S.N. Abdullah et al., 2013. Changes in leaf gas exchange, biochemical properties, growth and yield of Chilli grown under soilless culture subjected to deficit Fertigation. Aust J. Crop Sci., 7: 1582-1589.
Samota, M.K., M. Sasi, M. Awana, O.P. Yadov and M.S.V. Amitha et al., 2017. Elicitor-induced biochemical and molecular manifestations to improve drought tolerance in rice (Oryza sativa L.) through seed-priming. Front Plant Sci., 6: 934-934. DOI: 10.3389/fpls.2017.00934

Singh, N., D.R. Choudhury, G. Tiwari, A.K. Singh and S. Kumar et al., 2016. Genetic diversity trend in Indian rice varieties: An analysis using SSR markers. BMC Genetics, 17: 127-127.

Suprasanna, P., S.J. Mirajkar, Y.V. Patade and S.M. Jain, 2014. Induced mutagenesis for improving plant abiotic stress tolerance.

Shu, Q.Y., B. Foster and H. Nakagawa, 2011. Plant mutation breeding and biotechnology. Joint FAO/IAEA, Vienna, Austria.

Tanaka, A., N. Shikazono and Y. Hase, 2010. Studies on biological effects of ion beams on lethality, molecular nature of mutation, mutation rate and spectrum of mutation phenotype for mutation breeding in higher plants. J. Radiat. Res., 51: 223-233.

Uga, Y., K. Sugimoto, S. Ogawa, J. Rane and M. Ishitani et al., 2013. Control of root system architecture by DEEPER ROOTING 1 increases rice yield under drought conditions. Nature Genetics, 45: 1097-1104. DOI: 10.1038/ng.2725

Uga, Y., Y. Kitomi, E. Yamamoto, N. Kanno and S. Kawai et al., 2015. A QTL for root growth angle on rice 7 is involved in the genetic pathway of DEEPER ROOTING 1. Rice, 8: 8-8.

Wang, N., T. Long, W. Ya, L. Xiong and Q. Zhang et al., 2013. Mutant resources for the functional analysis of the rice genome. Molecular Plant, 6: 596-604.

Wei, F.J., G. Droc, E. Guiderdoni and Y. Hsing, 2013. International consortium of rice mutagenesis: Resources and beyond. Rice, 6: 39-39. DOI: $10.1186 / 1939-8433-6-39$

Widyanti, A., I. Sunaryo and A.D. Kumalasari, 2014. Reducing the dependency on rice as staple food in Indonesia-A Behavior intervention approach. J. ISSAAS, 20: 93-103.

Yoshihara, R., S. Nozawa and Y. Hase, 2013. Mutational effects of $\gamma$-rays and carbon ion beams on Arabidopsis seedlings. J. Radiat. Res., 54: 1050-1056. DOI: 10.1093/jrr/rrt074

Zain, N.A.M., M.R. Ismail, M. Mahmood, A. Puteh and M.H. Ibrahim, 2014. Alleviation of water stress effects on MR220 rice by application of periodical water stress and potassium fertilization. Molecules, 19: 1795-1819. 